\title{
Scheduling Coast Guard District Cutters
}

GERALD G. BROWN

ROBERT F. DELL

ROBERT A. FARMER

\author{
Operations Research Department \\ Naval Postgraduate School \\ Monterey, California 93943-5219
}

Operations Research Department

Naval Postgraduate School

United States Coast Guard

2100 2nd Street SW

Washington, DC 20593-0001

United States Coast Guard (USCG) districts schedule cutters 180 feet or less in length to weekly statuses (statuses is USCG jargon for assignments) from which they primarily respond to calls for search and rescue, law enforcement, and pollution control. The First Coast Guard District, based in Boston, has one of the largest scheduling problems: Each of 16 cutters is assigned weekly to one of six statuses to ensure patrol coverage, enforce equitable distribution of patrols, and honor restrictions on consecutive cutter statuses. When we state this quarterly scheduling problem as an elastic mixed-integer linear program, we obtain face-valid schedules-superior to manually prepared schedules for all measures of effectiveness considered-within a few minutes on a personal computer. Initial acceptance of the model was hampered by disruptive schedule revisions that resulted from minor changes in input. Modifications to preserve run-to-run persistence of solutions have brought success.

Semper Paratus -United States Coast

Guard Motto

\section{A}

1110 United States Coast Guard

(USCG) district commands face the problem of scheduling cutters 180 feet or

Copyright (c) 1996, Institute for Operations Research

and the Management Sciences

0092-2102/96/2602/0059\$01.25

This paper was refereed. less in length to weekly operational and maintenance statuses (statuses is USCG jargon for assignments) from which they primarily respond to calls for search and rescue, law enforcement, and pollution re-

PROGRAMMING, INTEGER-APPLICATIONS GOVERNMENT-US COAST GUARD 
sponse. The First USCG District has one of the largest scheduling problems, assigning each of 16 cutters weekly to one of six statuses to ensure patrol coverage, enforce equitable distribution of patrols, and honor restrictions on consecutive cutter statuses.

The First USCG District (Figure 1) extends from Maine to halfway down New Jersey and seaward to cover the ocean areas under US jurisdiction.

Manual scheduling of the first district cutters for four annual quarters takes a scheduler and his assistant two to three working days. (For six assignments, 16 cutters, and 13 weeks, the number of possible quarterly schedules is bounded by $6^{16 \times 13}$ $\approx 10^{62}$, and that's a lot.) Manual schedulers cannot be expected to consider all the minutia: They often overlook details about individual cutter use, do not distribute maintenance ideally, and even though patrolling is the primary mission of this fleet, they miss a number of required patrols. USCG issues the schedules, and they are followed. There is no way to know for sure whether the schedulers have overlooked better schedules. This motivates our search for improvements.

This type of cutter scheduling is different from other scheduling and timetabling problems. Covering the patrols is paramount, but patrols punctuated by energetic emergency responses fatigue crews and equipment, and these cutters have limited endurance. Periods of maintenance and crew rest are most effective when they fall

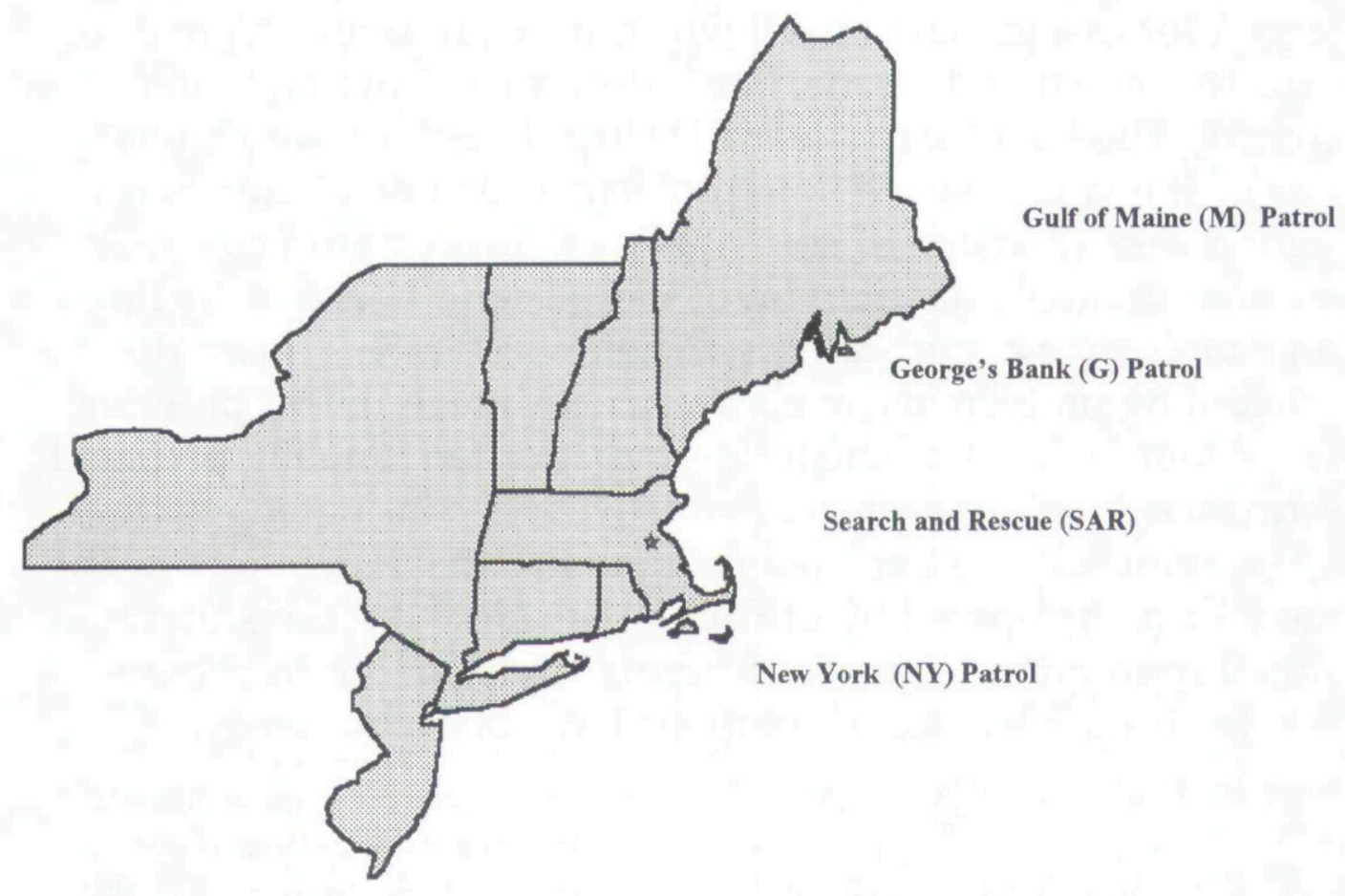

Figure 1: The First USCG District includes coastal ocean areas off the North-Eastern United States. Approximate patrol areas are shown where cutters have responsibility for search and rescue, law enforcement, and pollution response. 
in useful patterns, so scheduling these well is important too. Patrol requirements and maintenance availability change weekly, so it is impossible to design regular, cyclic rotations for each cutter between patrol and maintenance statuses.

Most ship scheduling work addresses commercial shipping problems: Ronen [1983] reviews models that essentially concern a fleet of ships moving goods from one or more supply points to various demand points. Researchers have paid some attention to military ship scheduling, although the problems they considered are often similar to those found in commercial cargo shipping, such as cargo deployment planning. Lally [1987], for example, assessed the required number of ships, and Lima [1988] bounded the elapsed deployment time. Some researchers have focused on scheduling a sequence of specific tasks, such as Bechtle [1984] and Cline, King, and Meyering [1992], who looked at scheduling USCG buoy-tenders. Some have focused on scheduling military ships to match ship capabilities to missions of varied durations: Brown, Goodman, and Wood [1990], Nulty and Ratliff [1986], and Goodman [1985] worked on annual employment periods for members of the US Navy Atlantic Fleet. Sibre [1977] scheduled USCG high-endurance cutters in the Pacific, and Darby-Dowman, Mitra, and Hajian [1992] did so for the Atlantic.

Farmer [1992] reviewed further contributions in these and related areas.

\section{Policies for Scheduling Cutters}

The First District has a fleet of 16 cutters (Figure 2):

- Three are 140-foot ice-breaking tugs

(USCG designated WTGB),
-Seven are 110-foot patrol boats (WPB), and

- Six are 82-foot patrol boats (WPB).

Each cutter is scheduled by week to be either in an operational status or in a maintenance status. The operational or "bravo" statuses include

-Bravo-2 (B-2), patrol status, during which the cutter must be underway or ready to get underway within two hours of notification to sail, and

-Bravo-6, -12, -24 (B-6, B-12, B-24), less operational readiness, during which cutters must be ready to get underway within six, 12, or 24 hours.

The First District schedules only B-2 and B-12 operational statuses. B-2 status weeks are assigned to cutters patrolling one of four geographical areas: Gulf of Maine, B-2(M); George's Bank, B-2(G); searchand-rescue, B-2(SAR); and New York, B-2(NY) (Figure 1). These patrol weeks fatigue both the crew and the cutter, so cutters are assigned no more than two consecutive weeks in any B-2 status or a single week in B-2(SAR) status. B-2 weeks are rotated equitably among all available cutters. Patrols close to homeport avoid long transit times to and from the patrol area. The less stringent readiness requirement of a B-12 week allows a cutter to conduct routine maintenance and training.

Not all cutter classes are eligible for every type of patrol year round. The 140foot WTGB tugs are reserved for ice-breaking during the winter. The 82 -foot patrol boats are not available for the SAR patrol during severe winter weather because icing conditions can cause stability problems for the cutters.

Cutters are scheduled to receive dedi- 

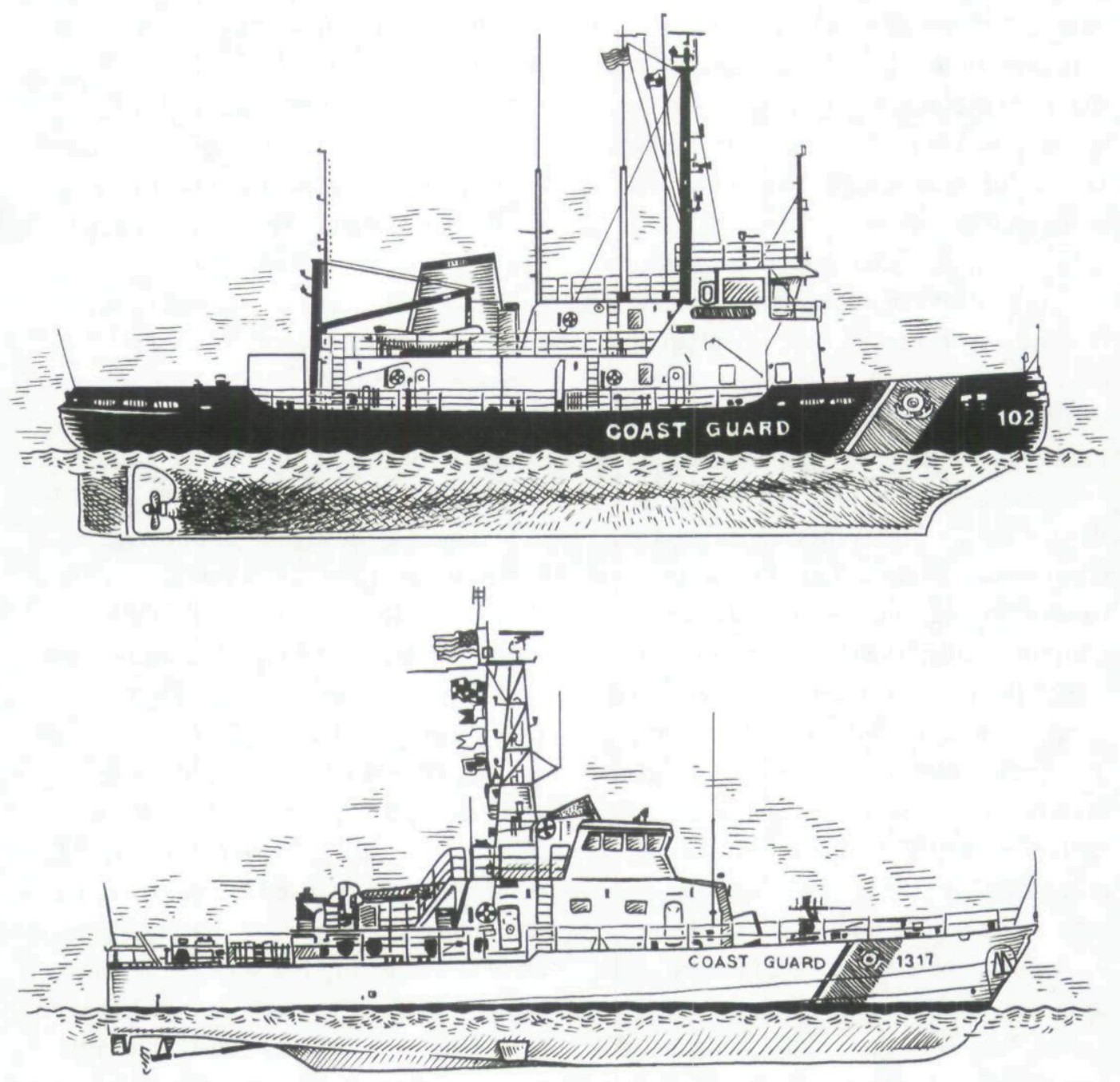

Figure 2: The 140-foot WTGB ice-breaking tug and the 110-foot WPB patrol boat. During winter months, ice-breaking tugs are not available for patrols, and smaller 82-foot cutters (almost identical in appearance to the 110-foot cutters) are not available for the SAR patrol during severe winter weather.

cated maintenance during "charlie" status weeks ("C"). A cutter so assigned is not expected to respond to anything but the gravest emergency. Maintenance periods of two consecutive weeks are preferred but are difficult to achieve with manual scheduling. A cutter may be completely removed from the district schedule during yard or dockside maintenance periods that are planned in advance with USCG Maintenance and Logistics Command. Cutters are also scheduled to make public appearances and patrol special events.

\section{CutS: A Cutter Scheduling Model}

With the advice of the First District schedulers, we developed a simple decision support system for scheduling cutters, called CutS, based on an elastic mixed- 
integer linear program that captures much of the detail and intent of the process (appendix). The elastic formulation allows schedules to violate, at a linear penalty cost per unit violation, requirements that cannot be met.

Each 13-week quarterly model is preceded by two weeks of fixed assignments from the end of the previous quarter. This is how we know whether and how to schedule consecutive weeks of patrols or pairs of maintenance weeks. The target number of maintenance weeks for a cutter may dictate scheduling a single week of maintenance, and if this happens we prefer it at the end of the quarter.

The minimum and maximum equitable numbers of patrols for each cutter must afford the scheduler some flexibility. The minimum equitable number of patrols for each cutter is arguably the total number of required patrols for all cutters divided by the number of cutters, unless a cutter has minimum maintenance requirements leaving insufficient weeks of availability; the maximum equitable number of patrols is considered to be the minimum plus two.

The difficulty of establishing meaningful measures of effectiveness for ship-scheduling problems is well documented by Soland [1982]. By adopting the same measures of effectiveness as the First District scheduler, we sought to

-Minimize the number of required patrol weeks missed,

-Minimize the transit time to patrol areas, and

-Equitably distribute the patrol weeks among cutters.

We developed costs and penalties for CutS to mimic the motives and rules of thumb of a good scheduler. The cost of assigning a cutter to a patrol is represented adequately by the hours underway at normal cruising speed from homeport to the patrol area (Table 1). Even though cutters generally remain in their homeport for a maintenance week, we use a transit time of two hours for any cutter assigned to maintenance: This is less than the smallest transit time in Table 1 but greater than the zero used for the B-12 status.

We want to satisfy all requirements for weekly patrols and maintenance, regardless of the transit time for cutters. Therefore, we derive elastic penalties for failing to satisfy those requirements from the transit-time matrix. We set penalties for single-cutter patrol requirements and maintenance penalties slightly greater than the largest transit time (for example, for the data in Table 1, 40 hours). Reasoning that violating a multi-cutter patrol requirement by one cutter is less serious than missing a single-cutter patrol completely, we moderated the multi-cutter patrol penalty (for example, we reduced it from 40 to 30 hours). The rationale for fairness penal-

\section{The number of possible quarterly schedules is bounded by $6^{16 \times 13} \approx 10^{62}$.}

ties of 25 hours per inequitable patrol assignment is that it is better to assign a cutter an extra patrol within 24 hours of homeport than to leave an area uncovered.

Normally, we would expect to discount penalties over time, thus tending to push problems into the future so they are easier to deal with. However, we have encoun- 


\begin{tabular}{lrrrr} 
Cutter & B-2(M) & B-2(G) & B-2(SAR) & B-2(NY) \\
\hline Adak & 17 & 9 & 9 & 3 \\
Wrangell & 3 & 6 & 6 & 17 \\
Sanibel & 6 & 3 & 3 & 6 \\
Monomoy & 6 & 3 & 3 & 6 \\
Jefferson-Island & 3 & 6 & 6 & 17 \\
Grand-Island & 3 & 3 & 3 & 11 \\
Bainbridge-Island & 17 & 9 & 9 & 3 \\
Pt-Bonita & 18 & 7 & 7 & 4 \\
Pt-Francis & 14 & 4 & 4 & 4 \\
Pt-Jackson & 18 & 11 & 5 & 5 \\
Pt-Hannon & 4 & 4 & 4 & 7 \\
Pt-Turner & 11 & 5 & 5 & 4 \\
Pt-Wells & 14 & 18 & 18 & 6 \\
Penobscot-Bay & 36 & 18 & 18 & 6 \\
Sturgeon-Bay & 36 & 18 & & 36 \\
Thunder-Bay & 6 & & & 7
\end{tabular}

Table 1: Patrol transit times for each cutter are shown in hours underway at normal speed from homeport to each patrol area. These times are minimized by CutS as a surrogate for the total quarterly transit time all cutters take to reach assigned patrol areas. These times are also used to normalize elastic penalties; for instance, the penalty incurred by assigning less than or more than two contiguous maintenance weeks is 40 hours, slightly longer than any single transit time.

tered so few violations using real USCG data that this has not been necessary.

\section{Comparisons with Manual Schedules}

As this research has progressed [Farmer 1992], CutS has evolved from a prototypic tool evaluated by comparing its schedules with historical manual schedules to an experimental generator of new schedules that were revised manually prior to publication to a tool that produces from the model a complete quarterly schedule that is published without change. During this evolution, scores of comparisons with manual schedules have contributed more than anything else to improvements in CutS and to its credibility with the USCG.

Expert schedulers-the intended beneficiaries of this work-have contributed a great deal from their experience to the de- velopment of CutS. But their advice was anecdotal and usually expressed in terms of what not to do. We have had to revise CutS frequently, sometimes on the spot. Flexibility has been key to success.

To adopt CutS, the 10 USCG districts required an extremely low-cost, site-by-site, stand-alone, single-purpose implementation. CutS had to reside on a modestly endowed personal computer (PC). We were able to use a 486/66 PC with four megabytes of random access memory, a system costing about $\$ 1,400$ (US).

We implemented CutS in GAMS [Brooke, Kendrick, and Meeraus 1992] and optimized it with a variety of solvers. We report results achieved with the mixedinteger linear programming solver XA [Sunset Software Technology 1993]. This 


\begin{tabular}{|c|c|c|c|c|c|c|}
\hline \multirow[b]{2}{*}{ Quarter } & \multirow[b]{2}{*}{$\begin{array}{l}\text { Total Cutter } \\
\text { Weeks }\end{array}$} & \multirow[b]{2}{*}{$\begin{array}{l}\text { Available } \\
\text { Cutter Weeks }\end{array}$} & \multicolumn{2}{|c|}{$\begin{array}{l}\text { Maintenance } \\
\text { Weeks }\end{array}$} & \multicolumn{2}{|c|}{$\begin{array}{l}\text { Missed Patrol } \\
\text { Weeks }\end{array}$} \\
\hline & & & Manual & CutS & Manual & CutS \\
\hline Spring & 208 & 162 & 68 & 68 & 1 & 0 \\
\hline Summer & 208 & 155 & 63 & 62 & 4 & 0 \\
\hline Fall & 208 & 150 & 70 & 70 & 6 & 0 \\
\hline Winter & 208 & 133 & 64 & 64 & 8 & 3 \\
\hline
\end{tabular}

Table 2: "Total Cutter Weeks" shows the product of 16 cutters working 13 weeks, "Available Cutter Weeks" deducts weeks when cutters are unavailable for work. The comparison of manual with CutS schedules (at five percent integrality tolerance) shows the number of maintenance (charlie) weeks assigned and the patrol weeks missed for each system. CutS missed far fewer patrols.

software and a reasonable complement of utilities cost about $\$ 4,000$ (US) per site.

Early in this effort, the First District provided manually prepared, published schedules for four consecutive quarters beginning with spring 1991. For each cutter and each week, these schedules show patrol weeks (but not specific patrol areas), maintenance weeks, and weeks unavailable (Table 2).

CutS scheduled each quarter using the same data the manual schedulers had used, except that we altered maintenance requirements (with permission) to even numbers to make it easy to schedule pairs of weeks. The resulting problems, after eliminating unnecessary variables and constraints, have about 850 equations, 650 binary variables, 550 continuous variables, and 7,100 nonzero elements in the constraint matrix.

CutS produces quarterly schedules with reasonable responsiveness (Table 3 ). However, things can slow down if CutS must seek too small an integrality gap-the difference between the cost of the schedule produced and a lower bound on that cost, expressed as a percentage of schedule cost. The First District schedulers find CutS schedules face valid, even when CutS only guarantees them to be within 10 percent of optimal. We can generate an annual sched-

Minutes to Guarantee Integrality Tolerance $(\%)$

\begin{tabular}{lcrrr} 
Quarter & $10 \%$ & $5 \%$ & $1 \%$ & \multicolumn{1}{c}{$0 \%$} \\
\hline Spring & 1.1 & 1.1 & 1.1 & 1.1 \\
Summer & 1.1 & 1.1 & 1.1 & 1.1 \\
Fall & 3.2 & 3.2 & 3.2 & 57.1 \\
Winter & 3.6 & 6.1 & 37.7 & 253.9
\end{tabular}

Table 3: It takes only a few minutes to complete a quarterly schedule with CutS using a 486/66 PC, GAMS 2.25, and the XA solver. Integrality tolerance is the largest admissible difference between the cost of a schedule and the lower bound on this cost, expressed as a percentage of schedule cost. The actual integrality gap achieved may be better than this tolerance. It takes manual schedulers more than two days to complete an equivalent set of four quarterly schedules. Even CutS schedules from the coarsest, 10-percent tolerance are face valid; this is fortunate because response time is generally much quicker for these than for other tolerances. 
ule within five percent of optimal by running the quarterly versions of CutS consecutively, including the required inputs for each model, in under two hours. This is a vast improvement over the two to three days for an equivalent manual exercise.

The fall and winter versions of CutS consistently take longer: This is probably because winter restrictions on the 140-foot ice-breaking tug, WTGB, and 82-foot WPB classes of cutters leave us with far fewer available cutter weeks and a more constrained, harder scheduling problem (Table 2).

Our primary mission is to assign required patrols to minimize the number of missed patrols. For the sample year (Table 2), manual schedules missed 19 patrol weeks, but CutS (at five percent integrality tolerance) missed only three. This is an enormous improvement.

Patrols should be equitably assigned among cutters. Equity is subjective and crews are likely to judge it by glancing at aggregate overall assignments (Table 4).

A quick comparison reveals the distribution of patrols among cutters, but not details like cutter-by-cutter unavailability. We can approximate the visual equity test quantitatively by comparing the standard deviations of patrols assigned. For instance, among WPB cutters available yearround, the sample standard deviation for total annual manual assignments is 2.55 patrol weeks, while for CutS this is 2.29 . During the spring, the manually scheduled

\begin{tabular}{lccccc} 
Cutter & Spring & Summer & Fall & Winter & Annual \\
\hline Adak & $4(4)$ & $4(4)$ & $4(4)$ & $4(3)$ & $16(15)$ \\
Wrangell & $4(4)$ & $1(4)$ & $5(6)$ & $6(6)$ & $16(20)$ \\
Sanibel & $6(6)$ & $5(4)$ & $5(6)$ & $5(5)$ & $21(21)$ \\
Monomoy & $3(4)$ & $6(6)$ & $3(3)$ & $5(6)$ & $17(19)$ \\
Jefferson-Island & $5(4)$ & $4(4)$ & $5(6)$ & $4(6)$ & $18(20)$ \\
Grand-Island & $5(5)$ & $3(4)$ & $5(6)$ & $2(3)$ & $15(18)$ \\
Bainbridge-Island & $5(4)$ & $6(4)$ & $5(5)$ & $7(6)$ & $23(19)$ \\
Pt-Bonita & $2(4)$ & $7(4)$ & $5(4)$ & $0(1)$ & $14(13)$ \\
Pt-Francis & $5(4)$ & $2(4)$ & $3(6)$ & $6(6)$ & $16(20)$ \\
Pt-Jackson & $2(4)$ & $3(3)$ & $6(4)$ & $4(5)$ & $15(16)$ \\
Pt-Hannon & $5(4)$ & $4(4)$ & $4(5)$ & $6(6)$ & $19(19)$ \\
Pt-Turner & $2(4)$ & $6(4)$ & $4(6)$ & $4(4)$ & $16(18)$ \\
Pt-Wells & $6(4)$ & $3(4)$ & $5(4)$ & $4(5)$ & $18(17)$ \\
Penobscot-Bay & $4(4)$ & $2(4)$ & $0(0)$ & $0(0)$ & $6(8)$ \\
Sturgeon-Bay & $4(4)$ & $1(4)$ & $0(0)$ & $0(0)$ & $5(8)$ \\
Thunder-Bay & $2(2)$ & $4(4)$ & $0(0)$ & $0(0)$ & $6(6)$
\end{tabular}

Table 4: Quarterly patrol weeks were assigned manually and (in parentheses) by CutS and totaled for the year. Cutters assigned three or fewer patrols probably had limited availability; the last three cutters are 140-foot WTGB ice-breaking tugs, and they are not available at all for fall or winter patrols. People often judge equity at a glance, and the standard deviation reflects this cursory judgment. Among 80 -foot and 110 -foot WPB cutters available year round, the sample standard deviation for total annual manual assignments is 2.55 patrol weeks, while for CutS this is 2.29 . 
standard deviation among all cutters is 1.41 patrol weeks but only 0.77 weeks with CutS; in the summer, CutS reduces 1.83 weeks to 0.57 .

These equity statistics are simplistic and superficial. A meaningful comparison requires a complete analysis of the details and reasoning underlying the schedule.

Nonetheless, people judge schedules at a glance, ignoring for the most part cutterby-cutter details, and standard deviations reflect this cursory judgment.

Clearly it's preferable for cutters to patrol close to homeport: This is the motive for minimizing equivalent transit hours in CutS. The USCG manual schedule for winter 1992 was assessed by CutS to require 458 equivalent transit hours, while the CutS optimization needed only 310 .

These values included penalties for missing patrols. During one four-week period when neither schedule had penalties, CutS reduced transit hours from 105 to 83 .

\section{How to Deal with Changes}

Published schedules must sometimes be revised. CutS uses optimization, and optimization has a well-earned reputation for amplifying small input data changes into wholesale revisions of prior solutions. This is a serious problem because major revision of an already published schedule can necessitate more planning, negotiation, and message traffic than the original did. We have had to deal with this.

Consider just one change. The schedule CutS suggested for summer 1994-a schedule the scheduler and cutter captains approved after slight modification-had considered the cutter Sanibel to be unavailable for three weeks beginning in late July (weeks $42-44$ on our fiscal calendar).
This unavailability was delayed for three weeks (to weeks 45-47).

Presented with this slight change, CutS suggested a breathtaking number of schedule revisions. For our purposes, a revision that inserts or deletes a B-2 patrol week is a major change. CutS prescribed 52 such

\section{We have had to revise CutS frequently, sometimes on the spot.}

major changes-changes in all but one week of the entire quarter-affecting the schedules of 11 of the 16 cutters. This revision is mathematically optimal and technically implementable but nonintuitive and managerially impractical.

We modified the optimization model in CutS to respond to small changes while retaining as much of an already-published schedule as practical-we call this desirable property "persistence" [Brown, Dell, and Wood 1995].

In our experience with CutS, a minor change in input does not alter the objective function value substantially, even when it causes lots of schedule revisions. Our problem isn't lack of good solutions but rather too many of them. Accordingly, for minor changes we can replace our objective function with an equivalent aspiration constraint to insure that revisions cost no more than the original schedule; we then modify CutS to revise with a surrogate objective, defined below, which preserves persistence.

In this case, the original schedule costs 570 transit hours, and we constrain the revision to cost no more. The surrogate cost 


\begin{tabular}{|c|c|c|c|c|c|c|c|c|c|c|c|c|c|}
\hline Cutter & 40 & 41 & 42 & 43 & 44 & 45 & 46 & 47 & 48 & 49 & 50 & 51 & 52 \\
\hline \multicolumn{14}{|c|}{ Revision with CutS } \\
\hline Adak & \multirow{2}{*}{\multicolumn{3}{|c|}{$\Delta$}} & & $\Delta$ & $\Delta$ & $\Delta$ & $\Delta$ & $\Delta$ & $\Delta$ & & & \\
\hline Wrangell & & & & & $\Delta$ & & $\Delta$ & & $\Delta$ & $\Delta$ & & & \\
\hline $\begin{array}{l}\text { Sanibel } \\
\text { Monomoy }\end{array}$ & $\Delta$ & & $\Delta$ & & & & & $\Delta$ & & $\Delta$ & $\Delta$ & & $\Delta$ \\
\hline $\begin{array}{l}\text { Jefferson-Island } \\
\text { Grand-Island }\end{array}$ & $\Delta$ & $\Delta$ & $\Delta$ & & & & & & & & $\Delta$ & $\Delta$ & $\Delta$ \\
\hline Bainbridge-Island & & & & & $\Delta$ & & $\Delta$ & & $\Delta$ & & & $\Delta$ & \\
\hline Pt-Bonita & & & & & $\Delta$ & & $\Delta$ & & $\Delta$ & $\Delta$ & $\Delta$ & $\Delta$ & \\
\hline Pt-Francis & $\Delta$ & & & & & & & & $\Delta$ & $\Delta$ & & $\Delta$ & $\Delta$ \\
\hline Pt-Jackson & & & $\Delta$ & & & & & & & & $\Delta$ & $\Delta$ & $\Delta$ \\
\hline Pt-Hannon & $\Delta$ & $\Delta$ & & & & & & $\Delta$ & & $\Delta$ & $\Delta$ & $\Delta$ & \\
\hline Pt-Turner & $\Delta$ & & $\Delta$ & & & & & $\Delta$ & & & $\Delta$ & & \\
\hline \multicolumn{14}{|l|}{ Pt-Wells } \\
\hline \multicolumn{14}{|l|}{ Penobscot-Bay } \\
\hline \multicolumn{13}{|l|}{ Sturgeon-Bay } & \\
\hline Thunder-Bay & & & & & & & & & & & & & \\
\hline
\end{tabular}

Revision with Persistent CutS

Adak

Wrangell

Sanibel

Monomoy

Jefferson-Island

Grand-Island

Bainbridge-Island

Pt-Bonita

Pt-Francis

Pt-Jackson

Pt-Hannon

Pt-Turner

Pt-Wells

Penobscot-Bay

Sturgeon-Bay

Thunder-Bay

Table 5: Persistence between schedule revisions can be enhanced. A revision of the summer 1994 First District schedule delays a three-week unavailability for the Sanibel from weeks 42-44 to weeks 45-47. A $\Delta$ represents a resulting major change to the original schedule (that is, B-2 patrol inserted, or deleted): These schedule revisions are counterintuitive and disproportionate to the slight input modification. After CutS is enhanced for persistence, a $\delta$ shows remaining major changes. The original schedule cost 570 transit hours with a three percent integrality gap: The revision is constrained to cost no more than $\mathbf{5 7 0}$ transit hours. The modified, persistent revision is much easier to promulgate and no more expensive to execute. 
of any Sanibel assignment is zero. For other cutters, the surrogate cost of assignments in the revision that persist with the original schedule is zero, exchanging B-2 patrols with $B-12$ or $C$ status costs 10 , and exchanging B-12 and C status costs 1 . For the summer 1994 revision, "persistent" CutS prescribed only 11 major changes (Table 5). Such revised models are typically much easier to solve than the corresponding original schedules: Here, the revision was about three times faster.

We have also been asked to fix individual assignments. Fixing assignment variables is easy. However, tinkering with an

\section{The goal is better schedules, not replacing schedulers.}

entire existing schedule by fixing individual variables is a tedious way to fine tune and too often unleashes unpleasant surprises.

In the real world, changes are inevitable. Decision support systems must accommodate changes, or their utility is limited, if not crippled. Optimization models, in particular, are much improved by incorporating explicit features for dealing with changes.

\section{Conclusions and Caveats}

CutS devises quarterly schedules that are superior to manually developed schedules: CutS misses fewer required patrols, assigns patrols closer to homeport, and more equitably distributes patrols among cutters.

CutS has recommended face-valid schedules that have been implemented without any changes by a scheduler. However, the goal is better schedules, not replacing schedulers. The real benefit may be helping schedulers evaluate feasible alternatives quickly. CutS offers far better alternatives.

Will the Coast Guard continue to use CutS? Although CutS offers impressive improvements, USCG districts have scheduled their cutters for a long time without bothering with computers, let alone mathematical models. Thus far, we have provided on-call support to the First District. Considering how quickly schedulers turn over, it may not be feasible for us to do this if all 10 districts adopt CutS. CutS is easy to use but admittedly suffers cosmetically for lack of a visually appealing graphical user interface: Our circular dilemma is that it makes sense to develop a slick interface only if the Coast Guard really wants to use it widely, but lack of such an interface limits demand.

Optimization has a nasty habit of prescribing tumultuous revisions based on small scenario-to-scenario input changes. We believe this explains much of the resistance to adoption of optimization-based decision support systems: Our modified, persistent version of CutS is an example of modeling for increased managerial acceptance.

\section{Acknowledgments}

We thank the following USCG First District schedulers, in order of their tenure: Lieutenants Robert Patton, Mike Sabellico, John Sharon, and Bill Stinehour. Farmer discovered this topic while sponsored by the USCG Research and Development Center. Dell has been supported, in part, by the Naval Postgraduate School research initiation program. Professor Kevin Wood (Naval Postgraduate School) has been a 
tough editor but generously donated his time to sharpen our exposition.

\section{APPENDIX}

The CutS formulation follows.

\section{Indices}

$i=$ cutter (for example, Adak, Wrangell, ....);

$k=$ statuses (for example, B-2(M), B-2(G), $\mathrm{B}-2(\mathrm{SAR}), \mathrm{B}-2(\mathrm{NY}), \mathrm{C})$ (the B-12 status is not explicitly contained in this index set); and

$t=$ week (for example, $1,2, \cdots, \mathcal{T}=15$ ).

\section{Data}

$\operatorname{COST}_{i k}=$ "cost" of assigning cutter $i$ to status $k$ (units for these costs and penalties are discussed below);

$R E Q_{k}=$ recommended number of cutters for patrol status $k$;

$R P E N_{k t}=$ penalty for scheduling less than the recommended number of cutters $\left(R E Q_{k}\right)$ for patrol status $k$ in week $t$ (cost per cutter);

$\underline{F A I R}_{i}, \overline{F A I R}_{i}=\underline{\text { minimum }}, \overline{\text { maximum }}$ equitable number of patrols for cutter $i$;

$F P E N=$ penalty for under- or overutilization of an equitable number of patrols (cost per patrol);

CHARLIE $_{i}=$ minimum number of maintenance weeks required for cutter $i$;

$C P E N_{t}=$ penalty incurred in week $t$ due to assignment of less than, or more than two contiguous maintenance weeks (cost per instance);

$\underline{F I X}_{i k t}, \overline{F I X}_{i k t}=\underline{\text { lower }}, \overline{\text { upper }}$ bound on assignment of cutter $i$ to status $k$ during week $t$ : This can be used to restrict assignments or to fix partial schedules such as the known statuses for two weeks preceding each quarter. In the absence of a restriction, $\underline{F I X} \equiv 0$ and $\overline{F I X} \equiv 1$;

$\overline{A S P I R E}=$ the maximum desired total "cost" of a quarterly schedule;

$\mathrm{CHANGE}_{i k t}=$ given a prior incumbent schedule with assignment of cutter $i$ to some status in week $t, C H A N G E_{i k t}$ is the penalty for changing the old incumbent status to a new candidate status $k$. In the absence of comparison with a prior schedule, $C H A N G E_{i k t} \equiv 0 \forall i, k, t$; and $\overline{C H A N G E}=$ the maximum desired total "change" of a quarterly schedule.

\section{Decision Variables}

assign $_{i k t}=1$ if cutter $i$ is assigned status $k$ in week $t$, and 0 otherwise;

$d r e q_{k t}=$ elastic variable measuring the number of cutters less than the recommended number for patrol status $k$ in week $t$;

$d{ }_{c o n} n_{i t}=$ elastic variable representing assignment of cutter $i$ to a noncontiguous maintenance week $t$;

$d 3 c_{i t}=$ elastic variable representing assignment of cutter $i$ to a third contiguous maintenance week $t$;

unfair $_{i}=$ elastic variable representing the number of inequitable patrols under- or over-assigned to cutter $i$;

cost $=$ total "cost" of a quarterly schedule:

This cost may be minimized, and is bounded by $\overline{A S P I R E}$; and

change $=$ total changes between a prior incumbent schedule and a new candidate schedule: This cost may be minimized, and is bounded by $\overline{C H A N G E}$.

\section{Formulation}

Subject to

$$
\sum_{i} a_{s s i g n} n_{i k t}=R E Q_{k}-d r e q_{k t} \quad \forall k \neq C, t .
$$

$\sum_{k} \operatorname{assign}_{i k t} \leq 1 \quad \forall i, t$.

$$
\begin{aligned}
& \sum_{t} \operatorname{assign}_{i C t} \geq \underline{\text { CHARLIE }}_{i} \quad \forall i, \\
& \operatorname{assign}_{i C 1}-\operatorname{assign}_{i C 2} \leq 0+\operatorname{dcon}_{i 1} \forall i, \\
& \operatorname{assign}_{i C t}-\operatorname{assign}_{i C t-1}-\operatorname{assign}_{i C t+1} \\
& \leq 0+\text { dcon }_{i t} \quad \forall i, 1<t<\mathcal{T} .
\end{aligned}
$$

$\operatorname{assign}_{i C T}-\operatorname{assign}_{i C T-1}$

$\leq 0+\operatorname{dcon}_{i \tau} \quad \forall i$. 


$$
\begin{aligned}
& \operatorname{assign}_{i C t}+\operatorname{assign}_{i \mathrm{Ct}-1}+\operatorname{assign}_{i \mathrm{Ct}-2} \\
& \leq 2+d 3 c_{i t} \quad \forall i, t>2 .
\end{aligned}
$$$$
\sum_{k \neq C} \sum_{t} \operatorname{assign}_{i k t} \geq \underline{F A I R}_{i}-\text { unfair }_{i} \quad \forall i,
$$$$
\sum_{k \neq C} \sum_{t} \text { assign }_{i k t} \leq \overline{\text { FAIR }}_{i}+\text { unfair }_{i} \quad \forall i .
$$$$
\sum\left(a s s i g n_{i k t}+a s s i g n_{i k t-1}+a s s i g n_{i k t-2}\right)
$$$$
\leq 2 \forall i, t>2 \text {. }
$$$$
\operatorname{assign}_{i B-2(\mathrm{SAR}) t}+\operatorname{assign}_{i \mathrm{~B}-2(\mathrm{SAR}) t-1} \leq 1
$$$$
\forall i, t>1 \text {. }
$$

$$
\begin{aligned}
\operatorname{assign}_{i k t} & \in\left\{\underline{F I X}_{i k t}, \overline{F I X}_{i k t}\right\} \forall i, k, t, \\
\text { dreq }_{k t} & \geq 0 \quad \forall k, t ; \\
d \operatorname{con}_{i t} & \geq 0 \quad \forall i, t ; \\
d 3 c_{i t} & \geq 0 \quad \forall i, t ; \text { unfair }_{i} \geq 0 \quad \forall i .
\end{aligned}
$$

$$
\begin{aligned}
& \sum_{i} \sum_{k} \sum_{t} \operatorname{COST}_{i k} a \operatorname{ssign}_{i k t} \\
& +\sum_{k} \sum_{t} R P E N_{k t} \text { dreq }_{k t \prime} \\
& +\sum_{i} \sum_{t} \operatorname{CPEN}_{t}\left(\text { dcon }_{i t}+d 3 c_{i t}\right) \\
& +\sum_{i}{\text { FPEN } \text { unfair }_{i}=\text { cost }} \\
& \text { cost } \leq \overline{\text { ASPIRE }} \text {, }
\end{aligned}
$$

$$
\begin{aligned}
& \sum_{i} \sum_{k} \sum_{t} C H A N G E_{i k t} \text { assign }_{i k t}=\text { change, } \\
& \text { change } \leq \overline{\text { CHANGE. }}
\end{aligned}
$$

\section{Minimize}

cost

or minimize

change.
The constraints and objectives are described below:

(1) The recommended number of cutters must be assigned to patrol $k$ or the shortfall assessed.

(6) (2) Each cutter may be assigned to at most one status each week. (Any cutter not assigned a status is assumed to be in status B-12.)

(3) A minimum number of maintenance weeks must be assigned to each cutter during the quarter.

(4-5) Maintenance should be assigned in two consecutive weeks: (4) assesses an

(8) elastic violation if a cutter $i$ is assigned non-contiguous maintenance in week $t$, even if this is the last week of the quarter, while (5) assesses a violation for a third contiguous maintenance week $t$.

(6) An equitable number of patrols should be assigned to each cutter, or the magnitude of inequity assessed.

(7) At most two consecutive patrols may be assigned to each cutter.

(8) A cutter should not be assigned to consecutive weeks of search-and-rescue patrols.

(9) Assignment variables are binary; elastic variables are non-negative.

(10) The full cost of a schedule includes assignment costs and elastic penalty costs. This cost is bounded by $\overline{A S P I R E}$.

(11) This penalty function assesses how much a revised candidate schedule differs from a prior incumbent schedule. This penalty is bounded by $\overline{C H A N G E}$.

(12) The objective may be to minimize total cost or to minimize changes from a prior incumbent schedule.

\section{References}

Bechtle, J. M. 1984, "Routing a USCG buoytender to service aids to navigation: A case of the traveling salesman problem," MS thesis, Naval Postgraduate School, Monterey, California.

Brooke, A.; Kendrick, D.; and Meeraus, A. 1992, GAMS: A User's Guide, Release 2.25, The Scientific Press, South San Francisco, 


\section{California}

Brown, G. G.; Dell, R. F.; and Wood, R. K. 1995, "Optimization and persistence," working paper.

Brown, G. G.; Goodman, C. E.; and Wood, R. K. 1990, "Annual scheduling of Atlantic fleet naval combatants," Operations Research, Vol. 38, No. 2, pp. 249-259.

Cline, A. K.; King, D. H.; and Meyering, J. M. 1992, "Routing and scheduling coast guard buoy tenders," Interfaces, Vol. 22, No. 3, pp. 56-72.

Darby-Dowman, K.; Mitra, G.; and Hajian, M. 1992, "Solution strategies for zero-one programming with a class of vehicle problem," presented at the EURO/TIMS Joint International Conference, Helsinki, Finland.

Farmer, R. A. 1992, "Scheduling coast guard district cutters," MS thesis, Naval Postgraduate School, Monterey, California.

Goodman, C. E. 1985, "Annual scheduling of Atlantic fleet naval combatants," MS thesis, Naval Postgraduate School, Monterey, California.

Lally, M. J. 1987, "Strategic allocation of sealift: A GAMS based integer programming approach," MS thesis, Naval Postgraduate School, Monterey, California.

Lima, N. R. 1988, "A column generation technique for a crises deployment planning problem," MS thesis, Naval Postgraduate School, Monterey, California.

Nulty, W. G. and Ratliff, H. D. 1986, "Interactive optimization methodology for fleet scheduling, PDRC 86-11," School of Industrial and Systems Engineering, Georgia Institute of Technology, Atlanta, Georgia.

Ronen, D. 1983, "Cargo ships routing and scheduling: Survey of models and problems," European Journal of Operational Research, Vol. 12, pp. 119-126.

Sibre, C. E. 1977, "A quadratic assignment/linear programming approach to ship scheduling for the US Coast Guard," MS thesis, Naval Postgraduate School, Monterey, California.

Soland, R. M. 1982, Proceedings of a Symposium on Cargo Ship Routing and Scheduling, SerialTM-69250, Institute for Management Science and Engineering, School of Engineering and Applied Science, George Washington University, Washington, DC.
Sunset Software Technology 1993, XA: Professional Linear Programming System GAMS Version 2.2, San Marino, California.

S. N. White, Captain, US Coast Guard, Chief, Search and Rescue Branch, First Coast Guard District, 408 Atlantic Avenue, Boston, Massachusetts 02210-3350, writes, “Dear Dr. Dell:

"I would like to thank you for the time and effort you spent to develop a patrol boat schedule for the First Coast Guard District during July, 1995. You produced a very workable and realistic schedule despite having to factor in numerous individual cutter requests and various scheduling constraints. The schedule which you produced met First Coast Guard District scheduling needs in all aspects. Although last minute operational needs required the original schedule to be modified slightly, the methodology behind your mathematical model has proved its effectiveness.

"Your assistance in this matter was greatly appreciated and I look forward to the opportunity to work with you again in the near future." 
Copyright 1996, by INFORMS, all rights reserved. Copyright of Interfaces is the property of INFORMS: Institute for Operations Research and its content may not be copied or emailed to multiple sites or posted to a listserv without the copyright holder's express written permission. However, users may print, download, or email articles for individual use. 